Britvin, S.N., et al., 2020, Cyclophosphates, a new class of native phosphorus compounds, and some insights into prebiotic phosphorylation on early Earth: Geology, v. 49, https://doi.org/10.1130/G48203.1

\title{
Cyclophosphates, a new class of native phosphorus compounds, and some insights into prebiotic phosphorylation on early Earth
}

Sergey N. Britvin, Michail N. Murashko, Yevgeny Vapnik, Natalia S. Vlasenko, Maria G. Krzhizhanovskaya, Oleg S. Vereshchagin, Vladimir N. Bocharov, and Maksim S. Lozhkin

\section{Supplementary materials}

Topographic coordinates of locality

Materials and Methods

Figures S1 and S2

Table S1 


\section{Topographic coordinates of locality (WGS84 coordinate system):}

Locality of the collected specimens: $\quad 31^{\circ} 12^{\prime} 53^{\prime \prime} \mathrm{N} ; 35^{\circ} 14^{\prime} 44^{\prime \prime} \mathrm{E}$

\section{Materials and Methods:}

Scanning electron microscopy (SEM) and electron microprobe analysis (EMPA). Chemical composition of the minerals was studied using a Hitachi S-3400N scanning electron microscope (SEM) which was equipped with an Oxford Instruments AzTec Energy X-Max 20 energy dispersive (EDX) detector. Electron microprobe analyses of cyclophosphates (Supplementary Table 1) were carried out by means of an INCA WAVE 500 wavelength-dispersive (WDX) spectrometer attached to a Hitachi S-3400N SEM. The analytical conditions were: $20 \mathrm{kV}$ accelerating voltage, $15 \mathrm{nA}$ beam current, $20 \mathrm{~s}$ peak counting time; $10 \mathrm{~s}$ background counting time. The following standards were used: chlorapatite (P-K series), trevorite (Fe- $K, \mathrm{Ni}-K$ ), diopside $\mathrm{CaMgSi}_{2} \mathrm{O}_{6}(\mathrm{Mg}-K, \mathrm{Ca}-K), \mathrm{MnCO}_{3}(\mathrm{Mn}-K)$, and $\mathrm{V}_{2} \mathrm{O}_{3}(\mathrm{~V}-K)$. No other elements with the atomic number greater than 4 were detected.

Electron backscatter diffraction (EBSD). Prior to EBSD study, polished sections containing cyclophosphates were treated using reactive ion etching (RIE) with $\mathrm{Ar}^{+}$ions, by means of an Oxford Instruments IonFab-300 ion beam etching system operated at $500 \mathrm{~V}$ acceleration voltage and $2.4 \mathrm{~mA} \mathrm{~cm}^{-2}$ flow current. EBSD measurements were carried out by means of a Hitachi S$3400 \mathrm{~N}$ scanning electron microscope equipped with an Oxford Instruments Nordlys-HKL EBSD detector, operated at $25 \mathrm{kV}$ and $1.5 \mathrm{nA}$ in a focused beam mode, using a $70^{\circ}$ tilted stage. Structural identification of studied cyclotetraphosphates (Supplementary Fig. 2) was carried out by matching the obtained EBSD patterns with the reference structure of $\mathrm{Ni}_{2} \mathrm{P}_{4} \mathrm{O}_{12}$ (Nord, 1983). 
Raman spectroscopy. Raman spectrum of $(\mathrm{Ni}, \mathrm{Fe})_{2} \mathrm{P}_{4} \mathrm{O}_{12}$ (Fig. 3) was obtained by means of a Horiba Jobin-Yvon LabRam HR800 spectrometer equipped with Ar-ion laser $(\lambda=514 \mathrm{~nm})$ and Olympus BX41 microscope using a 50× confocal objective. The spectrum was recorded with a resolution of $2 \mathrm{~cm}^{-1}$ and acquisition time $30 \mathrm{~s}$ with 20 scans. The spectrometer was calibrated against $520.7 \mathrm{~cm}^{-1}$ line of a silicon standard. 

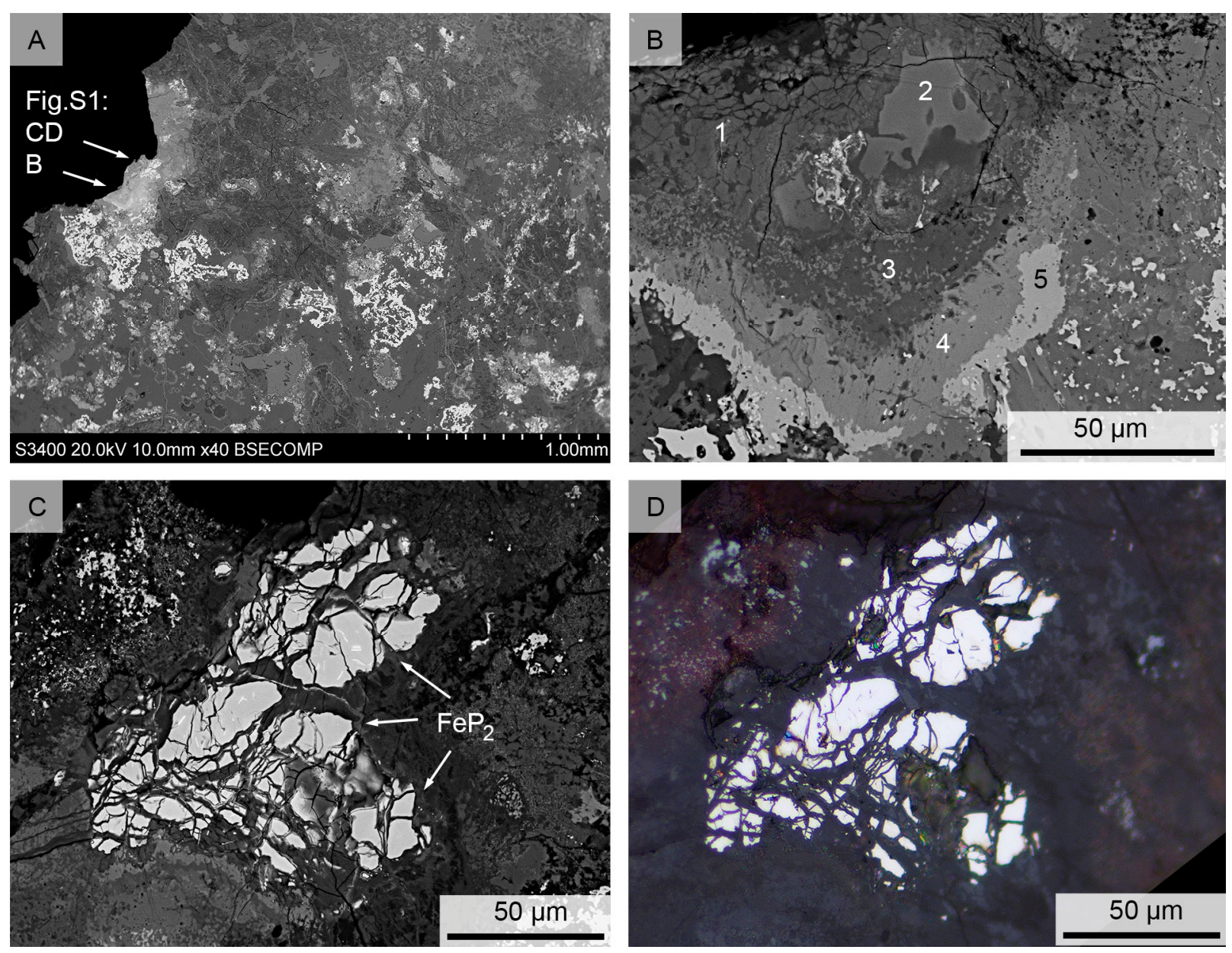

Figure S1. Cyclophosphate and associated minerals in the metamorphic rock of the Hatrurim Basin, Israel (supplement to Fig. 2). (A) General view of a polished section containing cyclophosphate. The fields corresponding to $(\mathrm{B})$ and $(\mathrm{C}, \mathrm{D})$ are marked by arrows. SEM BSE image. (B) Cyclophosphate and associated phosphate minerals. SEM BSE image of the area shown in Fig. 2B. Phosphate phases numbering: 1, $(\mathrm{Ni}, \mathrm{Fe})_{2} \mathrm{P}_{4} \mathrm{O}_{12} ; \mathbf{2},(\mathrm{Ca}, \mathrm{Ni})_{3}\left(\mathrm{PO}_{4}\right)_{2} ; \mathbf{3}$, $\mathrm{K}(\mathrm{Fe}, \mathrm{V}) \mathrm{P}_{2} \mathrm{O}_{7} ; \mathbf{4}, \mathrm{NaCa}(\mathrm{Fe}, \mathrm{Ni})_{3}\left(\mathrm{PO}_{4}\right)_{3} ; \mathbf{5}, \mathrm{FeNi}\left(\mathrm{PO}_{4}\right) \mathrm{O}$. (C) SEM BSE image of partially decomposed grain of zuktamrurite, $\mathrm{FeP}_{2}$, situated in the nearest vicinity to cyclophosphate. (D) The same area as in (c) captured in the reflected light. 

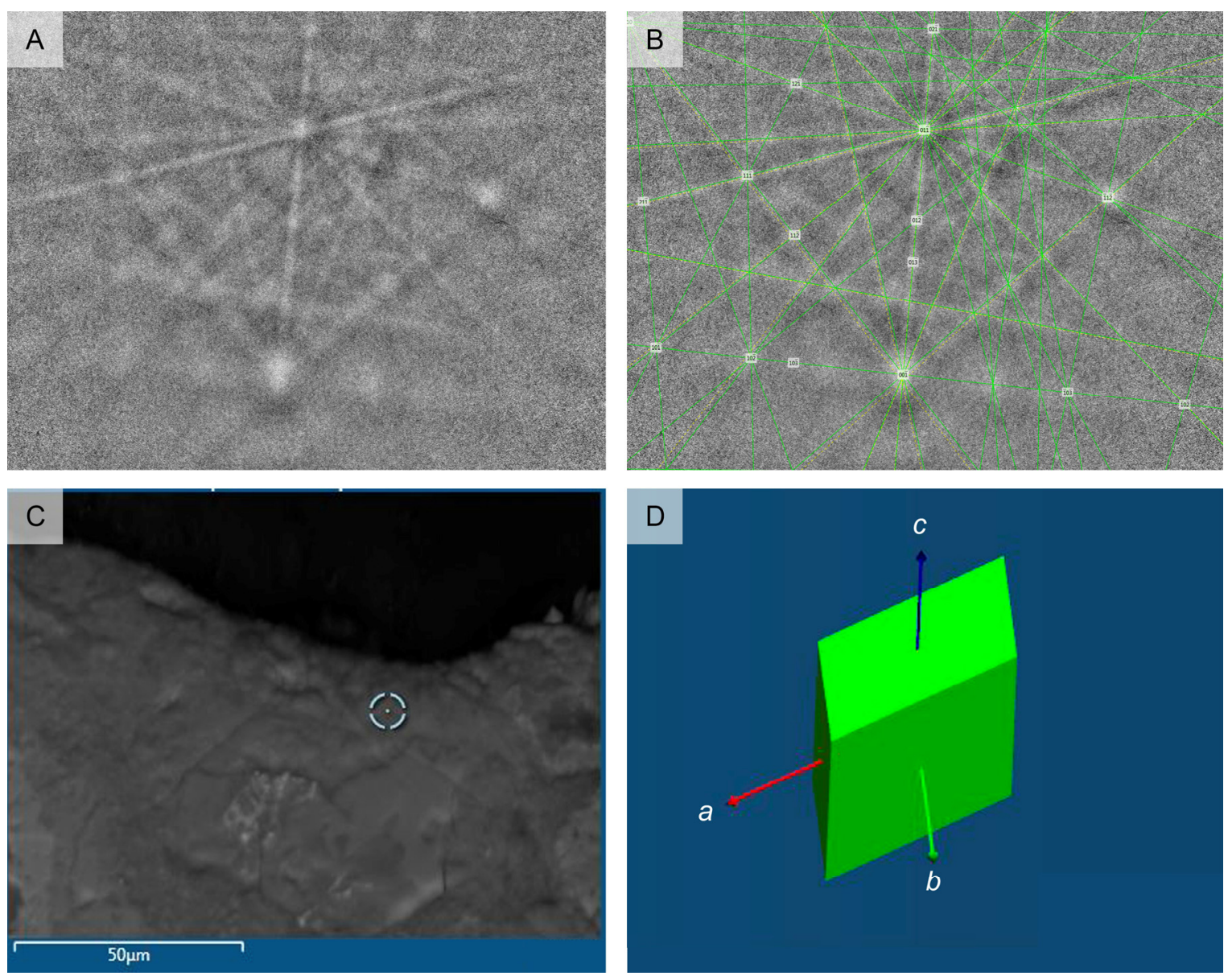

Figure S2. Electron backscatter diffraction of $(\mathrm{Ni}, \mathrm{Fe}){ }_{2} \mathrm{P}_{4} \mathrm{O}_{12}$. (A) An example of as-recorded electron backscatter pattern (EBSP). (B) The same EBSP indexed using the input data of synthetic $\mathrm{Ni}_{2} \mathrm{P}_{4} \mathrm{O}_{12}$ (Nord, 1983). Parameters of EBSP matching: $2 \times 2$ binning, 12 bands, mean angular deviation (MAD) $0.58^{\circ}$. (C) The point of a given EBSP take-off. (D) Crystallographic orientation of recorded $(\mathrm{Ni}, \mathrm{Fe})_{2} \mathrm{P}_{4} \mathrm{O}_{12}$ domain. 
Table S1. Chemical composition of Ni- and Fe-richest members of $\mathrm{Ni}_{2} \mathrm{P}_{4} \mathrm{O}_{12}-\mathrm{Fe}_{2} \mathrm{P}_{4} \mathrm{O}_{12}$ series

\begin{tabular}{lcr}
\hline & $\begin{array}{c}\text { Max. Ni } \\
\text { content }\end{array}$ & $\begin{array}{r}\text { Max. Fe } \\
\text { content }\end{array}$ \\
\hline Wt. \% \\
\hline $\mathrm{FeO}$ & 13.51 & 23.83 \\
$\mathrm{NiO}$ & 17.69 & 8.82 \\
$\mathrm{MgO}$ & 0.26 & 0.40 \\
$\mathrm{CaO}$ & 2.30 & 0.45 \\
$\mathrm{MnO}$ & 0.00 & 0.14 \\
$\mathrm{~V}_{2} \mathrm{O}_{3}$ & 0.13 & 0.12 \\
$\mathrm{P}_{2} \mathrm{O}_{5}$ & 66.72 & 66.94 \\
$\mathrm{Total}$ & 100.61 & 100.70 \\
\hline
\end{tabular}

Atoms per $M_{2} \mathrm{P}_{4} \mathrm{O}_{12}$ formula unit

\begin{tabular}{lll}
\hline $\mathrm{Fe}$ & 0.80 & 1.41 \\
$\mathrm{Ni}$ & 1.01 & 0.50 \\
$\mathrm{Mg}$ & 0.03 & 0.04 \\
$\mathrm{Ca}$ & 0.17 & 0.03 \\
$\mathrm{Mn}$ & 0.00 & 0.01 \\
$\mathrm{~V}$ & 0.01 & 0.01 \\
$\quad \Sigma M$ & 2.02 & 2.00 \\
$\mathrm{P}$ & 3.99 & 4.00 \\
\hline
\end{tabular}

